\title{
"Saltar era o seu negócio": o papel histórico dos não humanos na construção simbólica do Oeste a partir da indústria cultural dos rodeios
}

\author{
"Bucking was what he did:" the historical role of \\ nonhuman animals in the symbolic construction of the \\ West via the rodeo culture industry
}

\author{
Sandro Dutra e Silva \\ i Programa de Pós-graduação em Recursos Naturais do Cerrado/Universidade Estadual de Goiás. \\ Anápolis - GO - Brasil \\ orcid.org/0000-0002-0001-5726 \\ sandrodutr@hotmail.com
}

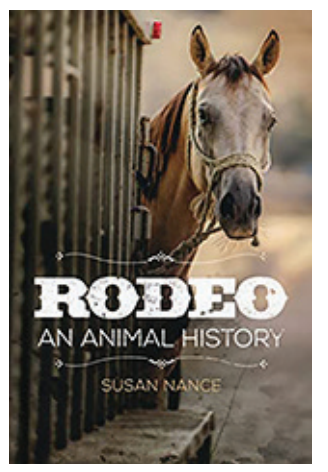

NANCE, Susan. Rodeo: an animal history. Norman: University of Oklahoma Press, 2020. 312p.

Talvez a mais significativa tese sobre os artefatos culturais do Oeste norte-americano tenha sido apresentada por Henry Nash Smith (2009), um dos fundadores do campo intelectual dos american studies. Smith promoveu um profundo debate sobre as raízes civilizatórias da cultura dos EUA, sendo cultuado como um dos mais influentes pesquisadores da tradicional escola historiográfica iniciada por Frederick Jackson Turner (Worster, 1992). O fascinante livro de Susan Nance (2020), Rodeo: an animal history, reforça essa tradição ao trilhar um novo caminho - original e instigante para compreender os símbolos e mitos do Oeste a partir do papel histórico dos não humanos. O seu estudo privilegia os animais de rodeio, entendidos pela autora como representação sui generis desse arcabouço cultural. Enquanto Smith privilegiava as personagens humanas, Nance procurou descrever os não humanos. Na obra, a indústria cultural do rodeio se manifesta como a instituição responsável por manter vivos os mitos da fronteira e seus atributos: rusticidade, virilidade, independência, resiliência, entre outros. E, nesse sentido, a principal influência teórica é o trabalho do historiador Richard White $(1991,1994)$ nas escolhas dessa nova abordagem do Oeste.

Importante ressaltar que a experiência pessoal da autora com o mundo rural foi uma energia capital para a pesquisa. Essa subjetividade se apresenta na problematização dos rituais do rodeio, como celebração coletiva da conquista humana sobre o território e os não humanos. E, por racionalizar o rodeio como "comoditização" do Oeste e dos seus símbolos: autodeterminação, independência e liberdade. Esse é um argumento essencial, diluído nos seis capítulos do livro, no qual os não humanos desempenham um papel protagonista.

O mérito de Nance é assumir, de forma engajada e competente, a tarefa desafiadora de dar sentido histórico ao papel dos cavalos, touros e novilhos na formação de hábitos 
fundantes e dos valores culturais do mundo rural nos EUA e no Canadá. Outro grande mérito é que a história animal proposta por Nance se desenvolve no diálogo com as personagens humanas - icônicas ou anônimas, porém coadjuvantes. As narrativas inserem os não humanos no universo dos peões de rodeios em suas diferentes especialidades como riders (peão de montaria em touros e cavalos), ropers (laçadores) e wranglers (operários e demais profissionais). Embora procurando historicizar os não humanos, a autora nos faz refletir sobre o contato interacional e as apropriações imagéticas de mitos e símbolos pela indústria cultural do rodeio. Os argumentos, portanto, foram construídos em um espaço cultural muito particular: as arenas de rodeio dos EUA e do Canadá. Mas, ao mesmo tempo, esse espaço estabelecia conexões com outros territórios culturais, povoados por animais selvagens e domesticados, como as terras públicas e os ranchos.

A base documental utilizada foi fundamental para reforçar os argumentos da pesquisa. E, ao mesmo tempo, dava ênfase à hipótese da construção do mito, na medida em que grande parte da documentação pertencia a arquivos, museus e instituições que preservam a memória e o patrimônio da cultura western. O uso pertinente da variedade de fontes foi fundamental para a construção dos argumentos e a elaboração das análises das personagens célebres e anônimas da história animal dos rodeios.

O livro explora, no entanto, um outro mito fundante (myth of animal consente), e amplamente ponderado pela autora, no qual os equinos e bovinos cumpriam um papel importante em reforçar o espírito do Oeste, por desempenhar (performance) sua natureza brutal nas arenas dos rodeios. Essa categoria foi muito bem explorada por Nance, ao utilizar com maestria a construção de narrativas históricas dos animais de rodeio. Um exemplo fascinante - ponto de partida e modelo analítico - é a narrativa da trajetória do icônico cavalo Steamboat. Esse animal simbolizava o mito do consentimento, e que pode ser resumido numa expressão utilizada para descrever sua personalidade: bucking was his business (Nance, 2020, p.65). Esse recurso metodológico se aplicou a outras personagens não humanas: Tipperary, Tanglefoot, Midnight, Black Diamond, Gravedigger, Cyclone, Tip Top, Coon, Hell Angel, War Paint, North of Yellowstone, Prince e Snowflake (bucking horses); Red Rock, Takin'Care of Business, V61, Tornado, Oscar, Bodacious, Mr. T, Dillinger, Little yellow Jacket, e Mudslinger (bulls).

Não apenas as celebridades não humanas dos rodeios receberam a atenção de Nance. Uma das narrativas mais fascinantes envolve Greasy Sal, uma desconhecida égua que chama a atenção da autora por aparecer e desaparecer rapidamente nas fontes analisadas. Nance descreve sua trajetória de forma muito sutil na obra, mas nos faz refletir sobre a dominação masculina dos rodeios, tanto em relação aos humanos quanto aos não humanos. Greasy Sal lança questionamentos sobre a dominação e reprodução da indústria cultural e os processos e inclusão e exclusão. Distinções e restrições das quais a maioria tem como fim perverso os matadouros (Erichsen, 2020). Assim a autora explora essa faceta da indústria cultural em estabelecer padrões de consumo, no qual a imagem idealizada engloba humanos e não humanos. Com sutileza a narrativa de Greasy Sal nos auxilia a compreender o universo de dominação masculina e conservadora do mundo ocidental.

O trabalho de Nance explora também os processos de resistência, sobretudo quando evidencia as lutas sociais contra a violência e o abuso contra os animais. O papel 
de associações e organizações de defesa dos animais ressalta a luta contra a barbárie entendida como expressão cultural, destacando outro valor simbólico dos não humanos na representação do espírito livre do Oeste.

Por isso, a principal contribuição desse livro está em não ser exclusivamente uma narrativa descritiva da história animal a partir do rodeio. Ele suscita reflexões profundas sobre os elementos culturais (históricos, sociológicos e antropológicos) e as estratégias sociais pela manutenção de hábitos tradicionais e muito conservadores. E, nesse sentido, a obra tem também um papel político em explicar determinados padrões da bandeira conservadora e republicana. Essas reflexões nos ajudam a compreender posicionamentos masculinos e conservadores da tradicional sociedade rural dos EUA e do Canadá, e a expansão desses valores na sociedade ocidental contemporânea. A grande lição para os historiadores é que eles não podem desconsiderar ou desprezar a convenção visual dos animais. Ao contrário, os historiadores interessados nos estudos dos animais precisam estar atentos para a construção social das imagens, suas representações e a relação prática entre humanos e não humanos no plano cultural.

\section{REFERÊNCIAS}

ERICHSEN, Lucas. A carne e o mar: o matadouro da praia de Santa Luzia, 1777-1853. Halac:

Historia Ambiental Latinoamericana y Caribeña, v.10, n.2, p.203-226, 2020.

NANCE, Susan. Rodeo: an animal history.

Norman: University of Oklahoma Press, 2020.

SMITH, Henry Nash. Virgin land: the American West as symbol and myth. Cambridge, MA: Harvard University Press, 2009.
WHITE, Richard. Animals and enterprise. In: Milner II, Clyde A.; O'Connor, Carol A.; Sandweiss, Martha A. (ed.). The Oxford history of the American West. New York: Oxford University Press, 1994. p.237-273.

WHITE, Richard. A new history of the American West. Norman: Oklahoma University Press, 1991.

WORSTER, Donald. Under western skies: nature and history in the American West. New York: Oxford University Press, 1992. 